\title{
The use of seclusion and restraint during I 5 years - a nationwide study in Finland
}

\author{
Alice Keski-Valkama*, Eila Sailas, Markku Eronen, Jouko Lönnqvist and \\ Riittakerttu Kaltiala-Heino
}

\author{
Address: Vanha Vaasa Hospital, P.O.Box 13, 65380 Vaasa, Finland
}

* Corresponding author

\author{
from WPA Thematic Conference. Coercive Treatment in Psychiatry: A Comprehensive Review \\ Dresden, Germany. 6-8 June 2007 \\ Published: 19 December 2007 \\ BMC Psychiatry 2007, 7(Suppl I):SI57 doi:10.1 I86/I47|-244X-7-SI-SI57
}

This abstract is available from: http://www.biomedcentral.com//47I-244X/7/SI/SI57

(c) 2007 Keski-Valkama et al; licensee BioMed Central Ltd.

\section{Background}

Internationally, concerns over the use of seclusion and restraint in psychiatric care have increased over the past decades. In Finland, restriction of freedom and use of coercion in psychiatry are regulated by the Mental Health Act of 1991. After its implementation, the Act (revision 2002) has become more restrictive and specified in relation to using coercion. Objective: This study investigated the nationwide trends in the use of seclusion and restraint in Finland over a fifteen-year span (1990-2004) that was characterised by legislative changes.

\section{Methods}

The data was collected during a predetermined week in 1990, 1991, 1994, 1998, and 2004 using the National Hospital Discharge Register and a structured postal survey of Finnish psychiatric hospitals.

\section{Results}

Notwithstanding the legislative changes, the use of seclusion and restraint did not change in Finland during 15 years.

\section{Conclusion}

Ethical and clinical considerations are discussed. 